\title{
Investigating the Effectiveness of an Augmented Reality Game to Enhance the Mathematics Learning Experience of Dyscalculic
}

Tanmay Debnath ( $\square$ imtanmaydebnath@gmail.com )

Indian Institute of Information Technology, Design and Manufacturing, Jabalpur

\section{Research Article}

Keywords: Augmented Reality, Dyscalculia, Mathematical models, User Experience

Posted Date: October 21st, 2021

DOl: https://doi.org/10.21203/rs.3.rs-996267/v1

License: (c) (1) This work is licensed under a Creative Commons Attribution 4.0 International License.

Read Full License 


\title{
Investigating the Effectiveness of an Augmented Reality Game to Enhance the Mathematics Learning Experience of Dyscalculic
}

\author{
Tanmay Debnath \\ PDPM IIITDM Jabalpur \\ 2017355@iiitdmj.ac.in
}

\begin{abstract}
Dyscalculic face a condition where they are unable to comprehend mathematical information. One of the main causes attributed to the same is the poor experience level at various levels of education. The main aim of this study is to design and implement augmented reality (AR) games, by integrating a visual method of performing mathematical operations, for enhancing the experience of Dyscalculic. S total of 31 participants was involved in this study. An online survey was conducted to measure the effectiveness of the developed AR game. The results of the paired-sample T-test indicated that participants in the experimental group have enhanced their mathematical performance level with a substantial decrease in the mean problem-solving time. The findings demonstrate that the proposed game can effectively enhance the performance of the dyscalculic using visual cue representation.
\end{abstract}

Keywords: Augmented Reality, Dyscalculia, Mathematical models, User Experience

\section{Introduction}

Dyscalculia is a specific learning disability in mathematics that is generally believed to be a permanent neurological condition that affects the processing of numerical and quantitative concepts [Munro, 2003]. Previous research studies suggest different prospects about the prevalence of dyscalculia. For example, [Peard, 2010] mentioned that dyscalculia is one of the common disorders among people with a mathematical disability. However, only $2 \%$ of the population, who are diagnosed with dyscalculia, have an actual neurological disorder. Thus proving that there is a significant gap between the concepts of mathematics and interaction. With the advancements of AR in education domains, the overall positive impact has been reviewed and proven by [Nincarean et al., 2013], in terms of specific subject contents to a large variety of audiences. However, it has been noted that there is no research conducted to understand the learning experience and interaction of dyscalculic in mathematics. This article described the development of an augmented reality-based game, with an additional visual cue method, that would help in enhancing the visual interaction of dyscalculic for solving mathematical problems.

In the following sections, the related work (Section 2), the research questions (Section 3), the methodology (Section 4), and followed by game design (Section 5), results (Section 6) and results (Section 7) have been thoroughly discussed.

\section{Related Work}

[Azuma et al., 2001] described AR as a system that supplements the real world with virtual objects that appear to coexist in the same space as the real world. In studies like mathematics, where the main task is to imagine the existence of numbers, AR can provide support to physically 
understand the importance of data representation. Many research studies have evaluated the effectiveness of AR in the education domain. For example, [Coimbra et al., 2015] has been proven that AR affects mathematical learning positively and interactively for the dyscalculic, thus confirming the need for an interactive system for learning mathematics. [Khan et al., 2019] found that AR helped the students to enhance their attention and concentration. In terms of mathematical learning, AR also has an impact which has been shown by [Cai et al., 2020]. Moreover, improvement of experiences using AR has also been reported by [López-Faican and Jaen, 2020]. However, there has been no such research that would be evaluating the experience of dyscalculic in mathematical learning. Hence, in this study, the designed system not only interacts and challenges the user to learn better but also enhances the user's learning over the course of game-play.

\section{Research Question}

The purpose of this study is to analyze the effectiveness of the developed augmented reality game in enhancing the mathematical learning experience of dyscalculic. The examined the statistical significance of the proposed design using problem-solving time as its controlling variable. The following research question was proposed:

- What is the overall effective and significance of using augmented reality game as a mathematical learning tool for dycalculic?

\section{Methodology}

The project aims to develop an AR system that could act as a medium for dyscalculic to interact with mathematics. For the same, there is a requirement to understand the current position of participants in terms of solving mathematical problems. Moreover, since analyzing experience is an integral part of this project, hence qualitative data were also collected immediately after the quantitative data collection to understand their present interactions with mathematics and how they have coped with it during their high school and higher studies years.

\subsection{Participants}

This study followed a mixed-design method where qualitative data was collected from the interview and quantitative data was collected using a Mathematics test. A total of 31 participants with age group 9-52 years old were involved in this study using Google form. The participants hail from varying geographical locations. All of the participants are suffering from clinically diagnosed dyscalculia, as confirmed by their clinical reports.

\subsection{Quantitative Data}

The quantitative data was acquired using a series of mathematical tests conducted using an online-based platform. The mathematical questions were asked to test their basic ability with mathematics, without using the intervention. A simple mathematical word problem was asked that almost simulates a real-life condition to understand their reaction in such situations. The question was a mixed form of multiplication and addition. From the test, mean problem-solving time and its standard deviation data were collected. The collected data were later analyzed using statistical software SPSS. 


\subsection{Qualitative Data}

The qualitative data was acquired using a series of interview questions, designed to understand the experience of dyscalculic in mathematics. The test was performed using two methods. Firstly, by using Google Forms where feedback on their mathematical learning experience was recorded. Secondly, using an online one-to-one video conferencing platform, more comprehensive data was collected, including their current work and learning environment. The main analysis was done by sentiment analysis, where a positive experience was given a ' + ' index whereas a negative index was given a '-' index. Based on the total accumulation of ' + ' and '-', the final verdict was determined.

\section{Game Design}

The proposed system is a manifestation of the ARCS model of motivation design, as theorized by [Li and Keller, 2018]. The ARCS model gives a descriptive idea of implementing Attention (A), Relevance (R), Confidence (C), and Satisfaction (S) into educational settings.

\subsection{Game Development}

The application has been developed using Unity Engine. The AR development has been done using Google ARCore. The backend development was carried out using C\#.

\subsection{Game Mechanics}

The implemented system has been developed using a marker-less-based environment. Figure 2 shows the mathematical tally cards that are used in the system for performing mathematical operations. The user has basic control over the environment where the main task would be to solve mathematical problems to find the shortest distance to the finish point, as shown in figure 1 (a).

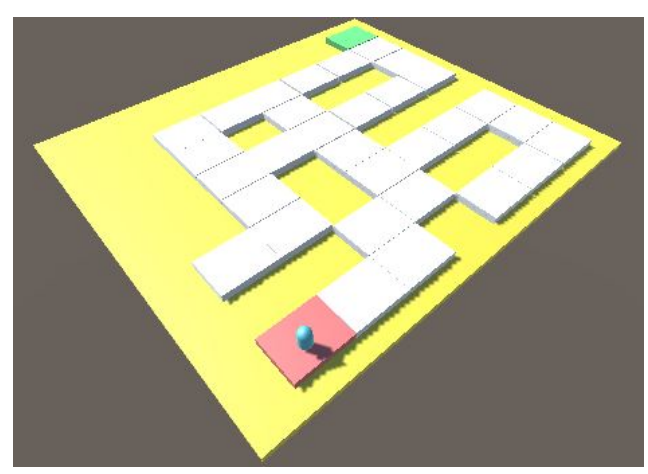

(a)

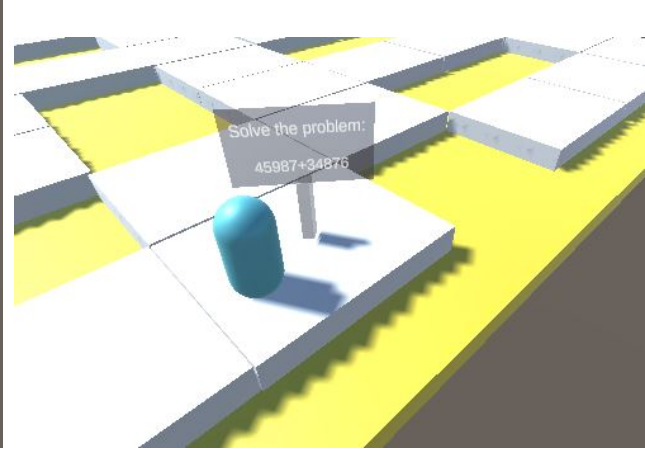

(b)

Figure 1: (a) The complete overview of the developed AR game. (b) The interaction of the body with the building blocks in the game

Figure 1(b) represents the extended view of the pop-up question. Every white block in the screen represents the state in which the player can move. The red block represents the starting of the game and the green block represents the finishing point in the game. By traversing through the correct number of blocks, the user has to reach the finishing point in the shortest distance possible. Each block has been given a single point and the least result obtained would be considered as the shortest distance possible. However, if the body touches the ground the game would immediately end and the user would have to start again from the red block. 


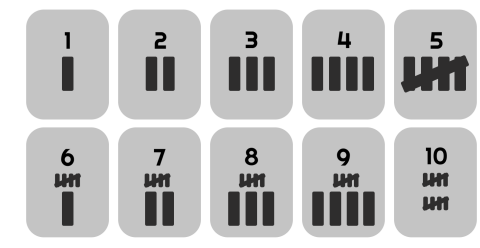

(a)

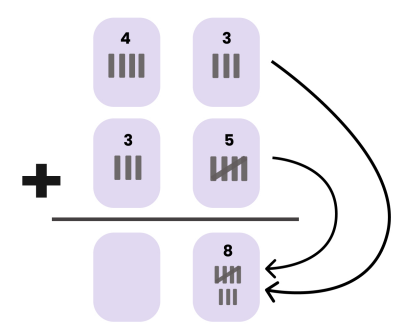

(b)

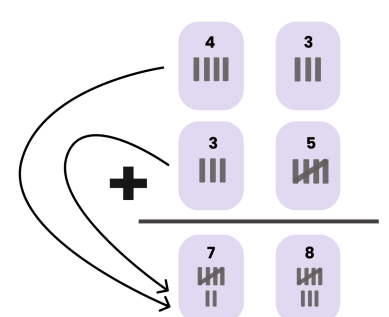

(c)

Figure 2: Represenation of addition using tally cards has been shown. For the addition of two numbers, the corresponding places of the two numbers are taken and placed as shown. The overall addition is represented by just combining the numbers in each place.

In this game, the mathematical operations have been designed to be performed using the tally cards methods as mentioned in figure 2 . The user would have to operate using the visual representation of numbers. The operations have to be performed from right to left. The tally method of addition has not been added into the AR game. Whenever the body would move from one block to another, there would be a mathematical question as shown in figure 1 (b). For the pilot experiment, column-wise movements have been decided to have the addition problems, whereas the row-wise movements have been decided to have small multiplication and large subtraction problems. After the final state, a new level starts with a new set of difficulty levels.

\section{Results}

The results section broadly analyzes the effectiveness of the developed AR game in terms of both qualitative and quantitative aspects of the implementation. For analyzing the quantitative data, the statistical data SPSS was used. The qualitative data contained experience values in terms of ' + ' and '-' where ' + ' implies positive experience and '-' implies negative experience; they were analyzed in terms of overall experience metrics as mentioned below.

\subsection{Quantitative Data Analysis}

For analyzing the quantitative data, paired-sample t-test was used, as shown in Table 2. The collected data includes problem-solving time, considering all the participants answered the questions correctly. The questions contained jumbled and nested usage of all basic mathematical operations. The questions didn't include any word problems because of possible high cognitive loading conditions, as experienced by users in the pre-intervention stage.

Table 1: Summary of the statistics of samples obtained before and after intervention

\begin{tabular}{lllll}
\hline & Mean (in Sec) & N & Std Deviation & Std Mean Error \\
\hline Before Intervention & 153.32 & 31 & 11.680 & 2.098 \\
After Intervention & 113.35 & 31 & 7.410 & 1.331 \\
\hline
\end{tabular}

Here, BI-AI would represent the paired-sample t-test for the before intervention-after intervention pair. For the below-mentioned test, the null hypothesis was considered to have no statistical significance. The significance value was achieved to be $1.56 \mathrm{E}-15$, which is less than the assumed value of 0.05 . Since the obtained significance value was less than that of the assumed value of significance level, we can reject the null hypothesis, thus confirming the fact that the 
intervention method is statistically significant. Moreover, it is evident from Table 1 that there is a significant reduction in the mean problem-solving time. Using the intervention, the study was able to achieve a $26.07 \%$ reduction in the mean problem-solving time. The effect size $(\eta)^{2}$ was calculated to be 0.5915 , which is considered to be a moderate effect [Cohen, 1977]. More specifically, the quantitative data analysis provides empirical evidence that people who were exposed to the intervention performed better than their previous attempts in terms of accuracy and problem-solving time.

Table 2: Summary of the statistical correlation and significance from the acquired data

\begin{tabular}{|c|c|c|c|c|c|c|c|c|}
\hline & \multirow[t]{2}{*}{ Mean } & \multirow[t]{2}{*}{$\begin{array}{l}\text { Standard } \\
\text { deviation }\end{array}$} & \multirow{2}{*}{$\begin{array}{c}\text { Std } \\
\text { Mean } \\
\text { Error }\end{array}$} & $\begin{array}{r}95 \% \mathrm{C} \\
\text { diffe }\end{array}$ & $\begin{array}{l}\text { of the } \\
\text { ence }\end{array}$ & \multirow[t]{2}{*}{$t$} & \multirow{2}{*}{$\begin{array}{l}\text { Degrees } \\
\quad \text { of } \\
\text { Freedom }\end{array}$} & \multirow[t]{2}{*}{ Significance } \\
\hline & & & & Lower & Upper & & & \\
\hline BI-AI & 39.968 & 14.773 & 2.653 & 34.549 & 45.368 & 15.064 & 30 & $1.556 \mathrm{E}-15$ \\
\hline
\end{tabular}

\subsection{Qualitative Data Analysis}

The data for the qualitative part was collected via an online medium for a period of 15 minutes, for each participant. The data includes texts that belong to one of two mentioned categories: ' + ' or ' - '. Table 3 shows the comparison of cases before and after the intervention.

Table 3: Summary of the statistics of samples obtained before and after intervention

\begin{tabular}{|c|c|c|c|c|c|}
\hline \multirow{2}{*}{$\begin{array}{l}\text { Q. } \\
\text { No }\end{array}$} & \multirow[t]{2}{*}{ Questions } & \multicolumn{2}{|c|}{ Before Intervention } & \multicolumn{2}{|c|}{ After Intervention } \\
\hline & & $\begin{array}{c}+ \\
\text { (Positive) }\end{array}$ & $\begin{array}{c}- \\
\text { (Negative) } \\
\end{array}$ & $\begin{array}{c}+ \\
\text { (Positive) }\end{array}$ & $\begin{array}{c}- \\
\text { (Negative) } \\
\end{array}$ \\
\hline 1 & $\begin{array}{l}\text { What was your experience with } \\
\text { mathematics in the test? (in } \\
\text { terms of solving the questions } \\
\text { methodically) }\end{array}$ & & 年 & tent & \\
\hline 2 & $\begin{array}{l}\text { How easy were the questions for } \\
\text { you? }\end{array}$ & & 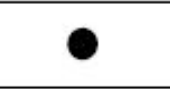 & 0 & \\
\hline 3 & $\begin{array}{l}\text { Did you feel any cognitive } \\
\text { loading (headache, nausea, etc.) } \\
\text { while performing the test? }\end{array}$ & 0 & & & 0 \\
\hline 4 & $\begin{array}{l}\text { Did you take help from any } \\
\text { calculator or family member } \\
\text { during the test? }\end{array}$ & O & & & - \\
\hline 5 & $\begin{array}{l}\text { How comfortable are you with } \\
\text { word-related problems, as of } \\
\text { now? }\end{array}$ & & O & & ○ \\
\hline 6 & $\begin{array}{l}\text { How good is the current method } \\
\text { for practicing mathematics, } \\
\text { considering interactions on a } \\
\text { day-to-day basis? }\end{array}$ & & 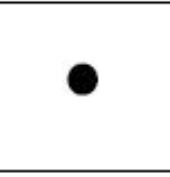 & - & \\
\hline
\end{tabular}


The data included in this analysis comprises those sections that relate to the usage of the intervention. The experience ranking provided in this study is the collective information gathered from all of the participants. The most dominating experience has been considered to be the overall experience of the group. For an instance, as mentioned in question 4, not everyone in the group took the help of calculators or some third-party solvers to solve the test. Collectively, a majority portion of participants did take help rather than solving it on their own. The study was unable to solve the issue with word problems. However, it has been noticed from the metadata review that the overall interaction and experience of participants with mathematics have enhanced. This provides empirical evidence that people who were exposed to the intervention performed better than their previous attempts in terms of enhanced interaction and experience.

\section{Discussion}

The results indicate that augmented reality games could be implemented as an intervention for mathematical learning of the dyscalculic. The results obtained are in line with the claims of (cite). The study provides an insight into the relationship between user interaction and learning using quantitative and qualitative evidence, thus answering the main research question of finding the statistical significance to learning in augmented reality environments. The generalizability of the results is limited by the number of participants attending the study and their level of dyscalculic behavior in their day-to-day lives. Further research is required to understand the effects of augmented reality applications in different age groups to find out the most suitable method of generalized learning.

\section{Conclusion}

For a mathematical disability like dyscalculia, where understanding the basics of mathematics becomes a challenge, advanced interaction technologies like AR can improve their learning experience. In this paper, an augmented-reality-based game has been presented for visual interaction with mathematical concepts, learning, and practice. The developed approach is unique mainly because of three reasons. First, the study is established based on the mathematics learning experience of dyscalculic, which has not been done previously. Second, this research provides an augmented reality-based solution for dyscalculic to interact with mathematics. Third, being implemented in mobile platforms made the game easily accessible from anywhere, thus reaching a wider user group.

The current work has a limitation. Currently, only addition and subtraction problems were considered for learning and practice. Further improvements would include more mathematical operations like multiplication, division, application of nested parentheses, etc. along with the development of advanced levels.

\section{Conflict of Interest}

The author declares no conflicts of interests.

\section{References}

[Azuma et al., 2001] Azuma, R., Baillot, Y., Behringer, R., Feiner, S., Julier, S., and MacIntyre, B. (2001). Recent advances in augmented reality. IEEE Computer Graphics and Applications, 21(6):34-47. 
[Cai et al., 2020] Cai, S., Liu, E., Shen, Y., Liu, C., Li, S., and Shen, Y. (2020). Probability learning in mathematics using augmented reality: impact on student's learning gains and attitudes. Interactive Learning Environments, 28:560-573.

[Cohen, 1977] Cohen, J. (1977). Chapter 3 - the significance of a product moment rs. In Cohen, J., editor, Statistical Power Analysis for the Behavioral Sciences, pages 75-107. Academic Press.

[Coimbra et al., 2015] Coimbra, M. T., Cardoso, T., and Mateus, A. (2015). Augmented reality: An enhancer for higher education students in math's learning? Procedia Computer Science, 67:332-339. Proceedings of the 6th International Conference on Software Development and Technologies for Enhancing Accessibility and Fighting Info-exclusion.

[Khan et al., 2019] Khan, T., Johnston, K., and Ophoff, J. (2019). The impact of an augmented reality application on learning motivation of students. Advances in Human-Computer Interaction, 2019:1-14.

[Li and Keller, 2018] Li, K. and Keller, J. (2018). Use of the arcs model in education: A literature review. Computers and Education, 122.

[López-Faican and Jaen, 2020] López-Faican, L. and Jaen, J. (2020). Emofindar: Evaluation of a mobile multiplayer augmented reality game for primary school children. Computers and Education, 149:103814.

[Munro, 2003] Munro, J. (2003). Dyscalculia: A unifying concept in understanding mathematics learning disabilities. Australian Journal of Learning Disabilities, 8(4):25-32.

[Nincarean et al., 2013] Nincarean, D., Bilal Ali, M., Abd halim, N., and Rahman, M. (2013). Mobile augmented reality: The potential for education. volume 103.

[Peard, 2010] Peard, R. (2010). Dyscalculia: What is its prevalence? research evidence from case studies. Procedia - Social and Behavioral Sciences, 8:106-113. International Conference on Mathematics Education Research 2010 (ICMER 2010). 